\title{
Discrepancies Between Medical and Pharmacy Records for Patients on Anti-HIV Drugs
}

\author{
Monique MR de Maat, Suzanne V Frankfort, Ron AA Mathôt, Jan W Mulder, Pieter L Meenhorst, \\ Eric CM van Gorp, Cornelis HW Koks, Richard MW Hoetelmans, Anthonius de Boer, and Jos H Beijnen
}

\begin{abstract}
OBJECTIVE: To compare and evaluate drug notations in outpatient medical records and in pharmacy records in a cohort of HIV1-infected patients treated with antiretroviral drugs.

METHODS: Data on 103 patients were obtained from January 1, 1998, through December 31, 1999, by medical chart review and collection of pharmacy records. Two analyses were performed. First, antiretroviral drugs and comedication in the pharmacy records were documented and compared with their appearance in the outpatient medical records. Second, a detailed comparison was performed at 5 time points during the study period for the antiretroviral drugs. Generic name, formulation, strength, and frequency of dosing as registered in the outpatient medical records were compared with those registered in the pharmacy records.

RESULTS: Total drug dispensation was 1607 (366 and 1241 antiretroviral drugs and comedication, respectively). The first screening resulted in a total discrepancy of $55.1 \%(n=885)$, of which $97.1 \%(n=859)$ was attributed to the comedication and $2.9 \%(n=26)$ to the antiretroviral drugs. The discrepancy for the antiretroviral drugs at the specific time points ranged from $5.1 \%$ to $12.6 \%$ when the generic name only was used, and from $7.1 \%$ to $17 \%$ when formulation, strength, and frequency of dosing were also taken into account.

CONCLUSIONS: The observed discrepancy between outpatient medical records and pharmacy records mainly concerns the comedication. For the antiretroviral drugs fewer, but still substantial, discrepancies were observed. These results indicate that full exchange of information concerning drug use in this population between general practitioners and specialists (infectious disease) is lacking.

KEY WORDS: antiretroviral therapy, discrepancy, outpatient medical record, pharmacy record.
\end{abstract}

Ann Pharmacother 2002;36:410-5.

In ndividuals infected with HIV-1 are frequently confronted with opportunistic infections and malignancies. Due to this comorbidity, these patients generally receive numerous drugs, prescribed by both general practitioners and the infectious disease specialists. A regimen consisting of $2 \mathrm{nu}-$ cleoside analog reverse transcriptase inhibitors (NRTIs) as a backbone in combination with a nonnucleoside reverse transcriptase inhibitor (NNRTI) or 1 or 2 protease inhibitor(s) (PI) is the current standard of treatment of HIV-1-

Author information provided at the end of the text.

Presented in part (abstract 287) at the Fifth International Congress on Drug Therapy in HIV Infection, Glasgow, UK, October 22-26, 2000.

This study was financially supported by ZAO Health Insurances, Amsterdam, Netherlands infection. ${ }^{\mathbf{1}}$ NNRTIs and PIs are extensively metabolized by the cytochrome P450 system, and are therefore subject to pharmacokinetic interactions when used in combination with drugs metabolized via the same pathways. ${ }^{2,3}$ In the Netherlands, the antiretroviral regimen of each HIV-1-infected individual is initiated and adjusted by the infectious disease specialist. The general practitioner only repeats the prescription of antiretroviral drugs and is mainly involved in the prescription of comedication.

HIV-1-infected patients obtain all of their prescribed drugs at their community pharmacy (except for drugs available through compassionate-use programs and research studies in the hospital), where a computer-based system documents each drug dispensation per patient. The involvement of different physicians, unaware of the drugs prescribed by colleagues, may lead to unwanted drug- 
drug interactions, potentially resulting in either increased frequency of adverse effects or failure of therapy due to reduced exposure to antiretroviral drugs.

It is important that each physician who is involved in the treatment of these patients is aware of the extent of drug use when assessing the patient's response to therapy in order to make appropriate therapeutic decisions (dosage adjustment, medication initiation, or discontinuation). In the hospital, this information is obtained from the outpatient medical record and from the patient by interview during routine visits at the outpatient clinic.

Corelli et al. ${ }^{4}$ performed a study investigating the discrepancy between patient-reported medication use and that documented in the medical record by healthcare providers in an HIV-infected population. The results showed differences for the as-needed class of drugs (56-92\%) as well as for drugs used chronically (9-54\%). Another trial ${ }^{5}$ compared computer-based prescription records with medical record drug entries for antihypertensive drugs. The information in the medical record and the prescription file from the outpatient pharmacy did not match in 5-14\% of the drug entries when only the drug name was taken into account. Nonmatching dose information ranged from $14 \%$ to $21 \%$. To our knowledge, no studies have been reported in which outpatient medical records from HIV-1-infected individuals were compared with pharmacy records.

The objective of this study was to compare drug notations in outpatient medical records and in pharmacy records in a cohort of HIV-1-infected patients treated with antiretroviral drugs. The outcome of this study may aid in further optimization of the complex pharmacotherapy of HIV-1-infected individuals with drug prescriptions from different sources.

\section{Methods}

\section{PATIENTS AND DATA COLLECTION}

HIV-1-infected patients, treated at the outpatient clinic of the Department of Internal Medicine, Slotervaart Hospital, Amsterdam, Netherlands, were asked to give their written approval for use of their pharmacy records. The institutional review board of the Slotervaart Hospital approved the study protocol.

A retrospective chart review was performed; drug notations appearing in the pharmacy record were compared with the medical record in the hospital from January 1, 1998, through December 31, 1999. In the Netherlands, computer-based systems document each drug dispensation per patient and are known to be complete when it concerns recording of drug deliveries. ${ }^{6}$ Pharmacy records are thus regarded the "gold standard" in this study. The community pharmacies were contacted and asked for their cooperation by providing the pharmacy records of these patients. Community pharmacies in the Netherlands are using different computerbased systems for recording drug dispensation. These different systems, and the fact that not every patient has been registered with the current community pharmacy for the same period, results in different follow-up of pharmacy records. If pharmacy records had overlap with 1997 or 2000 , selections were made; only drugs that were stopped after January 1, 1998, or were initiated before January 1, 2000, were included in the analysis.

Data were collected from the medical records during the complete study period, but the analysis was only done for the period covered by each patient's pharmacy record. Each drug notation in the medical record made at a routine visit of the patient at the outpatient clinic, and information about drug use mentioned in correspondence between the infectious disease specialist, other specialists in the hospital, and the patient's general practitioner were documented. Drug name, drug formulation, strength, frequency of dosing, and the dates of initiation and termination of the drug were obtained.

Data from the pharmacy records and the medical records were incorporated in a database in Visual FoxPro 6.0 (Microsoft Corporation, Redmond, WA). Since the medical records often did not contain all information needed for the collection of data (mainly the exact date of initiation and termination of comedication were lacking), assumptions had to be made to perform the analysis (Table 1).

\section{ANALYSIS}

\section{Generic Name Only}

Generic names of antiretroviral drugs and comedication in the outpatient medical records were documented and compared with their appearance in the pharmacy records. Using the documented drugs in the pharmacy record as a criterion, a drug was recorded as a match when the same drug appeared in the outpatient medical record. The concordance was determined by calculating the ratio of matching drugs and total number of dispensed drugs; discrepancy is then the percentage that is nonconcordant. Drugs were classified according to the Anatomical Therapeutical Chemical (ATC) classification index. ${ }^{7}$ The first level (anatomic main group, i.e., the site at which treatment is directed) of the ATC code was used to determine the discrepancy in the different groups of comedication. Plasters, topical pharmacy-made products, and similar formulations that are not classified in an ATC-code group were classified as "miscellaneous" in group Z. For the antiretroviral drugs, the discrepancy was subdivided into each drug separately.

\section{Generic Name, Formulation, Strength, Dosing Frequency}

A detailed comparison was performed at 5 time points during the study period for the antiretroviral drugs only. The time points that were chosen for the analysis were: May 1, 1998; October 1, 1998; March 1, 1999; August 1, 1999; and December 1, 1999. Each of these time points resulted in a different cohort of patients, since not every patient had a pharmacy record that started January 1, 1998, and continued until December 31, 1999. In the first part of this analysis, drug notations appearing in the pharmacy record at the specific time points were compared with those in the outpatient medical record and, if identical, were regarded as a match. This comparison was done on generic name, regardless of the brand name that was prescribed or dispensed. As with the first analysis, concordance was determined by calculating the ratio of matching drugs and number of total dispensed drugs in that cohort at that time point; discrepancy is then the percentage that is nonconcordant.

The second part of this analysis focused on the formulation, strength, and dosing frequency per day of the antiretroviral drugs. These components of drug use in the outpatient medical records were compared with those in the pharmacy records, and concordance was again calculated by determining the ratio of matching drugs and total dispensed drugs in that cohort. For both analyses, the assumption was made that Combivir (a coformulation of zidovudine and lamivudine) was not equal to the constituent drugs separately. This assumption was made for practical rea-

Table 1. Assumptions Made to Incorporate Data from Medical Records into the Database

\begin{tabular}{|ll|}
\hline Time of Data Collection $^{\text {a }}$ & Incorporated into Database \\
\hline Beginning of the year & March 15 \\
Only year & June 15 \\
Only month & month 15 \\
No start date & date of visiting outpatient clinic \\
No stop date & December 31, 2000
\end{tabular}

aDate of initiation and/or termination of comedication as mentioned in medical records. 
sons, because 1 record for Combivir in the pharmacy record ( 1 dispensed) would otherwise be associated with 2 records in the medical notes.

\section{Results}

The data from pharmacy records and outpatient medical records of $103 \mathrm{HIV}-1$-infected patients (95 men) were included in this study. The median age of these patients at baseline was 43 years (interquartile range $38-50$ ). Duration of follow-up ranged from 2 months through 2 years (mean $1.4 \mathrm{y}$ ), with a total drug history of 148.3 years.

\section{ANALYSIS}

\section{Generic Name Only}

In this cohort of 103 patients, the total number of drugs dispensed was 1607, with antiretroviral drugs accounting for $22.8 \%(\mathrm{n}=366)$ and comedication accounting for $77.2 \%(\mathrm{n}=1241)$. The total discrepancy during the period from January 1, 1998, through December 31, 1999, was $55.1 \%(\mathrm{n}=885)$. Within each group, the discrepancy for the antiretroviral drugs and the comedication was $7.1 \%$ (n $=26)$ and $69.2 \%(n=859)$, respectively.

The percentage of discrepancy of the different ATCcode groups of comedication is presented in Table 2. High discrepancy was mainly observed in the miscellaneous group $(\mathrm{Z}, 96.7 \%)$, the group of the sensory organ agents (S, 94.4\%), drugs used for the urogenital tract and sex hor-

\begin{tabular}{|c|c|c|c|c|c|}
\hline \multirow{2}{*}{$\begin{array}{l}\text { ATC-Code } \\
\text { Group }^{\mathrm{a}}\end{array}$} & \multirow{2}{*}{$\begin{array}{l}\text { Total No. } \\
\text { of Drugs }\end{array}$} & \multicolumn{2}{|c|}{ Match } & \multicolumn{2}{|c|}{ Discrepancy } \\
\hline & & $n$ & $\%$ & $n$ & $\overline{\%}$ \\
\hline A & 194 & 83 & 42.8 & 111 & 57.2 \\
\hline B & 24 & 14 & 58.3 & 10 & 41.7 \\
\hline C & 35 & 11 & 31.4 & 24 & 68.6 \\
\hline D & 169 & 22 & 13 & 147 & 87 \\
\hline$G$ & 24 & 3 & 12.5 & 21 & 87.5 \\
\hline $\mathrm{H}$ & 18 & 10 & 55.6 & 8 & 44.4 \\
\hline J & 238 & 118 & 49.6 & 120 & 50.4 \\
\hline L & 12 & 8 & 66.7 & 4 & 33.3 \\
\hline$M$ & 55 & 11 & 20 & 44 & 80 \\
\hline $\mathrm{N}$ & 182 & 53 & 29.1 & 129 & 70.9 \\
\hline $\mathrm{P}$ & 20 & 9 & 45 & 11 & 55 \\
\hline $\mathrm{R}$ & 109 & 33 & 30.3 & 76 & 69.7 \\
\hline$S$ & 36 & 2 & 5.6 & 34 & 94.4 \\
\hline V & 4 & 1 & 25 & 3 & 75 \\
\hline Z & 121 & 4 & 3.3 & 117 & 96.7 \\
\hline \multicolumn{6}{|c|}{$\begin{array}{l}\text { ATC code = Anatomical Therapeutical Chemical code. } \\
\text { a } A=\text { gastrointestinal tract and metabolism; } B=\text { blood and blood-form- } \\
\text { ing organs; } C=\text { cardiovascular agents; } D=\text { dermatologic agents; } G= \\
\text { urogenital tract and sex hormones; } H=\text { systemic hormonal prepara- } \\
\text { tions; } \mathrm{J}=\text { systemic antimicrobial drugs } \mathrm{L}=\text { oncolytics and immune } \\
\text { modulators; } \mathrm{M}=\text { musculoskeletal agents; } \mathrm{N}=\text { central nervous system; } \\
\mathrm{P}=\text { antiprotozoa; } \mathrm{R}=\text { respiratory tract } \mathrm{S}=\text { organ of senses; } \mathrm{V}=\text { anti- } \\
\text { dotes, treatment of alcoholism; } \mathrm{Z}=\text { miscellaneous. }\end{array}$} \\
\hline
\end{tabular}

mones (G, 87.5\%), and dermatologic agents (D, 87\%), whereas a relatively low discrepancy was observed for the systemic hormonal preparations $(\mathrm{H}, 44.4 \%)$, drugs for the blood and blood-forming organs (B, 41.7\%), and oncolytics and immune modulators ( $\mathrm{L}, 33.3 \%)$.

In this population, the 10 most frequently coadministered drugs were trimethoprim/sulfamethoxazole (TMP/ SMX), loperamide, temazepam, cetirizine, miconazole, diclofenac, fluconazole, acyclovir, azithromycin, and doxycycline (Table 3 ). The discrepancy for each drug varied between $23 \%$ and $88 \%$, and was relatively high for miconazole (88\%), temazepam (73.3\%), diclofenac $(72.7 \%)$, and acyclovir (71.4\%). Relatively low discrepancy was observed for TMP/SMX (23\%), doxycycline (31.6\%), fluconazole $(38.1 \%)$, and cetirizine $(40.7 \%)$.

The antiretroviral drugs presented a discrepancy of $7.1 \%$. Drugs that had a large contribution to this discrepancy were zidovudine (16.7\%), ritonavir (10.8\%), nevirapine (10.4\%), and Combivir (10\%) (Table 4). Zalcitabine was not included in this analysis because it was not part of any antiretroviral regimen in this population during the follow-

\begin{tabular}{|c|c|c|c|c|c|}
\hline \multicolumn{6}{|c|}{$\begin{array}{l}\text { Table 3. Discrepancy in the } 10 \text { Most } \\
\text { Frequently Coadministered Drugs }\end{array}$} \\
\hline \multirow[b]{2}{*}{ Drugs $^{a}$} & \multirow{2}{*}{$\begin{array}{l}\text { Total No. } \\
\text { of Drugs }\end{array}$} & \multicolumn{2}{|c|}{ Match } & \multicolumn{2}{|c|}{ Discrepancy } \\
\hline & & $\mathbf{n}$ & $\%$ & $\mathrm{n}$ & $\%$ \\
\hline TMP/SMX & 39 & 30 & 77 & 9 & 23 \\
\hline Loperamide & 33 & 11 & 33.3 & 22 & 66.7 \\
\hline Temazepam & 30 & 8 & 26.7 & 22 & 73.3 \\
\hline Cetirizine & 27 & 16 & 59.3 & 11 & 40.7 \\
\hline Miconazole & 25 & 3 & 12 & 22 & 88 \\
\hline Diclofenac & 22 & 6 & 27.3 & 16 & 72.7 \\
\hline Fluconazole & 21 & 13 & 61.9 & 8 & 38.1 \\
\hline Acyclovir & 21 & 6 & 28.6 & 15 & 71.4 \\
\hline Azithromycin & 19 & 10 & 52.6 & 9 & 47.4 \\
\hline Doxycycline & 19 & 13 & 68.4 & 6 & 31.6 \\
\hline
\end{tabular}

Table 4. Discrepancy in Antiretroviral Drugs, Presented as Percentage of Discrepancy for Each Drug Separately

\begin{tabular}{|c|c|c|c|c|c|}
\hline \multirow[b]{2}{*}{ Drug } & \multirow{2}{*}{$\begin{array}{l}\text { Total No. } \\
\text { of Drugs }\end{array}$} & \multicolumn{2}{|c|}{ Match } & \multicolumn{2}{|c|}{ Discrepancy } \\
\hline & & $\mathrm{n}$ & $\%$ & $\mathrm{n}$ & $\%$ \\
\hline Nevirapine & 67 & 60 & 89.6 & 7 & 10.4 \\
\hline Combivir & 50 & 45 & 90 & 5 & 10 \\
\hline Lamivudine & 67 & 66 & 98.5 & 1 & 1.5 \\
\hline Zidovudine & 12 & 10 & 83.3 & 2 & 16.7 \\
\hline Didanosine & 4 & 4 & 100 & 0 & 0 \\
\hline Stavudine & 62 & 58 & 93.5 & 4 & 6.5 \\
\hline Indinavir & 23 & 22 & 95.7 & 1 & 4.3 \\
\hline Ritonavir & 37 & 33 & 89.2 & 4 & 10.8 \\
\hline Nelfinavir & 16 & 15 & 93.7 & 1 & 6.3 \\
\hline Saquinavir & 28 & 27 & 96.4 & 1 & 3.6 \\
\hline
\end{tabular}


up period. Abacavir, efavirenz, delavirdine, and amprenavir were not marketed at the time of analysis, but were available through so-called compassionate-use programs. Patients who were receiving these antiretroviral drugs as part of their therapy obtained them through the outpatient clinic and hospital pharmacy of the Slotervaart Hospital and not via their community pharmacy, thus discrepancy for these drugs could not be determined.

\section{Generic Name, Formulation, Strength, Dosing Frequency}

The results of the second analysis, in which 5 cohorts at different time points during the study period were formed, are presented in Table 5. The number of patients in these cohorts increased with time, because more pharmacy records were taken into account in the most recent cohorts. Fewer than 3 drugs per person were used, in spite of the conventionally used triple therapy. This is explained by the use of Combivir. Another explanation, of minor concern, is the compassionate-use programs in the hospital.

Using the generic name only, the discrepancy in the 5 different cohorts fluctuated from $5.1 \%$ to $12.6 \%$, whereas the discrepancy for the analysis when formulation, strength, and dosing frequency were taken into account fluctuated from $7.1 \%$ to $17 \%$. This more detailed comparison focusing on the 5 time points showed discrepancies that were overall somewhat higher than those in the first analysis.

\section{Discussion}

With the comparison of drug notations over a defined period of time, we found discrepancy between the 2 systems evaluated. This showed that 1 of the physicians involved was not aware of all of the medications being used, possibly resulting in problems such as drug-drug interactions.

The observed total discrepancy between outpatient medical records and pharmacy records mainly concerned the comedication. The high discrepancy in ATC-code group Z and the group of drugs used dermatologically may not be clinically relevant in most cases, but discrepancy in groups of the musculoskeletal agents, the central nervous system, the respiratory tract, and cardiovascular agents may be re- garded relevant. To interpret the relevance of high discrepancy, it is important to know the frequency of prescribing of certain drugs; those from groups with high discrepancy could be drugs that are rarely prescribed. Miconazole, temazepam, diclofenac, and acyclovir are among the 10 most frequently coadministered drugs. Miconazole is primarily used dermatologically. Temazepam, diclofenac, and acyclovir are used systemically (acyclovir is also used dermatologically), but are not susceptible to major drug-drug interactions. Nevertheless, in addition to the potential of drug interactions, it is also important to be aware of the drug use of each patient if adverse events occur. Without complete knowledge of the medication regimens, it is not possible to make a correct evaluation of the efficacy and/or toxicity of drugs, especially in this population in which multiple-drug regimens are very common.

The discrepancy in drug notations of the antiretroviral drugs was $7.1 \%$ in the first analysis. Discrepancy was observed for all antiretroviral drugs, with zidovudine showing the highest percentage. Because the discrepancy in antiretroviral drugs was not restricted to Combivir and lamivudine or zidovudine, the assumption to evaluate Combivir as a single drug could not have influenced the results. Antiretroviral drugs, like lamivudine and stavudine, with relatively low discrepancy, are the drugs most frequently used in this population; lamivudine and stavudine were part of the antiretroviral regimen of 67 and 62 patients, respectively, whereas 12 patients were prescribed zidovudine as part of the antiretroviral regimen. The drugs that are susceptible for drug-drug interactions, PIs and NNRTIs, showed relatively low, but substantial discrepancy.

The second analysis at the 5 time points using generic name only showed a discrepancy between $5.1 \%$ and $12.6 \%$. As a consequence of a more detailed analysis, the discrepancy was slightly higher compared with that shown in the first analysis. While the community pharmacy uses the prescribed daily units and the total amount of units dispensed to calculate the duration of drug exposure of an antiretroviral drug, the infectious disease specialist knows exactly the duration of drug exposure as he/she is the one who initiates and stops the use of these drugs. The infectious disease specialist can, for instance, discontinue an an-

\begin{tabular}{|c|c|c|c|c|c|c|c|c|c|}
\hline \multirow[b]{3}{*}{ Cohort } & \multirow[b]{3}{*}{ Patients (n) } & \multirow{3}{*}{$\begin{array}{l}\text { Total No. } \\
\text { of Drugs }\end{array}$} & \multirow[b]{3}{*}{ Drugs/Patient } & \multicolumn{4}{|c|}{ Match } & \multirow{2}{*}{\multicolumn{2}{|c|}{ Discrepancy (\%) }} \\
\hline & & & & \multicolumn{2}{|c|}{$\mathbf{I}^{\mathbf{a}}$} & \multicolumn{2}{|c|}{$I I^{\mathbf{b}}$} & & \\
\hline & & & & $\mathrm{n}$ & $\%$ & $n$ & $\%$ & $a^{a}$ & $\overline{I I^{b}}$ \\
\hline May 1, 1998 & 38 & 99 & 2.6 & 94 & 94.9 & 92 & 92.9 & 5.1 & 7.1 \\
\hline October 1, 1998 & 49 & 134 & 2.7 & 124 & 92.5 & 117 & 87.3 & 7.5 & 12.7 \\
\hline March 1, 1999 & 62 & 159 & 2.6 & 139 & 87.4 & 132 & 83 & 12.6 & 17 \\
\hline August 1, 1999 & 82 & 212 & 2.6 & 190 & 89.6 & 183 & 86.3 & 10.4 & 13.7 \\
\hline December 1, 1999 & 98 & 247 & 2.5 & 224 & 90.7 & 216 & 87.4 & 9.3 & 12.6 \\
\hline
\end{tabular}


tiretroviral regimen because of virologic failure, while the community pharmacy believes that this regimen is still in use based on the patient's pharmacy records. This could explain the somewhat higher discrepancy in drug exposure at a specific time point.

When strength, frequency of dosing, and formulation were taken into account, the discrepancy increased to values between $7.1 \%$ and $17 \%$. This was primarily due to differences in or lack of documentation of the formulation and strength of the antiretroviral drug (ritonavir liquid and capsule, and stavudine 30 and $40 \mathrm{mg}$ ). West et al. ${ }^{8}$ showed similar results in their study on the completeness of medical records for drug therapy relative to a database of dispensed pharmaceuticals. Of the 501 medical records reviewed, $11 \%$ of dispensed nonsteroidal antiinflammatory drugs (NSAIDs) were not entered into the medical record as having been prescribed to the patient. Comparable to our analysis in which discrepancy was obtained at specific time points, those investigators abstracted data from the medical record 1 month before the date the NSAID was dispensed.

In the Netherlands, the prescription of antiretroviral drugs is primarily assigned to the treating physician (infectious disease specialist) of the HIV-1-infected patient, whereas the general practitioner as well as other physicians at the outpatient clinic can be involved in the prescribing of comedication. The infectious disease specialist informs the general practitioner on a regular basis about changes in the course of the disease, antiretroviral regimen, and inititation or discontinuation of comedication. However, information about changes in the drug regimen performed by the general practitioner hardly ever reaches the specialist. In this case, the only source of information for the infectious disease specialist is the patient. Unfortunately, patients visit the outpatient clinic approximately every 3-4 months, and do not always remember the details about their prescribed drugs. Studies ${ }^{9,10}$ show that a patient's recall of drug use increases when drugs are used chronically, and is better for drugs used recently than for drugs used earlier. The infectious disease specialist is usually notified of the prescription of drugs by other specialists at the outpatient department of the hospital by letters, which are kept in the medical records as additional information. The lack of exchange of all information by different parties involved, however, results in incomplete or absent drug notations in the medical records in the hospital.

That full exchange of information is pivotal became clear from an observation we made during this study. ${ }^{11} \mathrm{We}$ noticed from the pharmacy records that some patients were using both St. John's wort and nevirapine. Both agents were recorded in the pharmacy record, but the use of St. John's wort was not documented in the medical record. This alerted us to further investigate the exposure to nevirapine when St. John's wort was used concomitantly, because earlier published data ${ }^{12}$ showed that lowered indinavir concentrations occur with concomitant use of St. John's wort. We showed that St. John's wort also decreased nevirapine concentrations by increasing its oral clearance, probably by induction of the cytochrome $\mathrm{P} 450$ enzyme system. Decreased nevirapine concentrations may eventually result in treatment failure by the development of nevirapine-resistant virus. In this case an herb, which is often not documented in the pharmacy records, showed that full awareness of all drug use is very important to optimize therapy.

Discrepancy between medical records and pharmacy records has not been investigated intensively thus far. Both Leister et al. ${ }^{13}$ and Christensen et al. ${ }^{5}$ determined the completeness of records for drugs ordered to and received by outpatients. They found discrepancies in drug names of $36 \%$ and $5-14 \%$ of the records, respectively, and in dosage information of $61 \%$ and $14-21 \%$, respectively. Although both groups of researchers used on-site clinic pharmacies for the collection of data, discrepancies varied. Compared with these results, the discrepancy of comedication determined with use of generic name only in this study was relatively high, but may be the result of data from 2 separate institutions of recording of drug notations. This discrepancy of comedication will probably be even higher when records are examined at specific time points or within specific time windows. Discrepancy of antiretroviral drugs in both analyses was relatively low. This can probably be explained by the fact that only 1 prescriber (infectious disease specialist) was involved.

\section{Summary}

The observed discrepancy between drug notations in outpatient medical records compared with pharmacy records was mainly determined by comedication. Antiretroviral therapy has shown less but still substantial discrepancy (up to 17\%). Discrepancy in drug notations of different sources may jeopardize effective therapy and lead to problems such as unwanted drug-drug interactions resulting in adverse effects. Our results indicate that full exchange of information concerning drug use in this population is lacking, but pivotal.

Monique MR de Maat PharmD, PhD Student, Department of Pharmacy \& Pharmacology, Slotervaart Hospital, Amsterdam, The Netherlands

Suzanne V Frankfort, Pharmacy Student, Department of Pharmacy \& Pharmacology, Slotervaart Hospital

Ron AA Mathôt PharmD PhD, Hospital Pharmacist, Department of Pharmacy \& Pharmacology, Slotervaart Hospital

Jan W Mulder MD PhD, Infectious Disease Specialist, Department of Internal Medicine, Slotervaart Hospital

Pieter L Meenhorst MD PhD, Infectious Disease Specialist, Department of Internal Medicine, Slotervaart Hospital

Eric CM van Gorp MD PhD, Infectious Disease Specialist, Department of Internal Medicine, Slotervaart Hospital

Cornelis HW Koks PharmD, Hospital Pharmacist, Department of Pharmacy \& Pharmacology, Slotervaart Hospital

Richard MW Hoetelmans PharmD PhD, Department of Pharmacy \& Pharmacology, Slotervaart Hospital

Anthonius de Boer MD PhD, Associate Professor, Faculty of Pharmacy, Department of Pharmacoepidemiology and Pharmacotherapy, University of Utrecht, Utrecht, Netherlands

Jos H Beijnen PharmD PhD, Professor, Department of Biomedical Analysis, Research Group Drug Toxicology, University of Utrecht; 
Hospital Pharmacist/Clinical Pharmacologist, Head, Laboratory Division, Department of Pharmacy \& Pharmacology, Slotervaart Hospital

Reprints: Monique MR de Maat PharmD, Department of Pharmacy \& Pharmacology, Slotervaart Hospital, Louwesweg 6, 1066 EC Amsterdam, The Netherlands, FAX 31-20-5124753, E-mail apmod@ slz.nl

\section{References}

1. Carpenter CCJ, Cooper DA, Fischl MA, Gatell JM, Gazzard BG, Hammer SM, et al. Antiretroviral therapy in adults. Updated recommendations of the International AIDS Society-USA Panel. JAMA 2000;283: 381-90.

2. Joly V, Yeni P. Non nucleoside reverse transcriptase inhibitors. AIDS Rev 1999;1:37-44.

3. Sommadossi J-P. HIV protease inhibitors: pharmacologic and metabolic distinctions. AIDS 1999;13(suppl 1):S29-40.

4. Corelli RL, Guglielmo BJ, Kapusnik-Uner JE, McMaster JR, Greenblatt RM. Medication usage patterns in patients with human immunodeficiency virus infection: a comparison of patient-recorded medication usage with medical chart review. DICP 1991;25:1374-8.

5. Christensen DB, Williams B, Goldberg HI, Martin DP, Engelberg R, LoGerfo JP. Comparison of prescription and medical records in reflecting patient antihypertensive drug therapy. Ann Pharmacother 1994;28: 99-104.

6. Herings RMC, Leufkens HGM. Community pharmacy networks in pharmacoepidemiology. In: Hartzema AG, Porta M, Tilson HH, eds. Pharmacoepidemiology: an introduction. 3rd ed. Cincinnati: Harvey Whitney Books, 1998:405-20.

7. Anatomical Therapeutical Chemical (ATC) classification index including defined daily doses (DDDs) for plain substances. Oslo: World Health Organisation Collaborating Centre for Drug Statistics Methodology, 1994.

8. West SL, Strom BL, Freundlich B, Normand E, Koch G, Savitz DA. Completeness of prescription recording in outpatient medical records from a health maintenance organization. J Clin Epidemiol 1994;47:16571.

9. Van den Brandt PA, Petri H, Dorant E, Goldbohm RA, Van de Crommert S. Comparison of questionnaire information and pharmacy data on drug use. Pharm Weekbl Sci 1991;13:91-6.

10. West SL, Savitz DA, Koch G, Strom BL, Guess HA, Hartzema A. Recall accuracy for prescription medications: self-report compared with databases information. Am J Epidemiol 1995;142:1103-12.

11. de Maat MMR, Hoetelmans RMW, Mathôt RAA, van Gorp ECM, Meenhorst PL, Mulder JW, et al. Drug interaction between St John's wort and nevirapine. AIDS 2001;15:420-1.

12. Piscitelli SC, Burstein AH, Chaitt D, Alfaro RM, Falloon J. Indinavir concentrations and St John's wort. Lancet 2000;355:547-8.

13. Leister KA, Edwards WA, Christensen DB, Clark H. A comparison of patient drug regimens as viewed by the physician, pharmacist and patient. Med Care 1981;29:658-64.

\section{EXTRACTO}

OBJETIVO: Comparar y evaluar las anotaciones efectuadas en los récords médicos y en los récords de farmacia de pacientes ambulatorios para un cohorte de pacientes infectados con el HIV-1 tratados con medicamentos antirretrovirales.

MÉTODOS: Los datos de 103 pacientes fueron recopilados durante el período comprendido entre del 1ro de enero al 31 de didiembre de 1999, mediante la revisión de los récords médicos y los de la farmacia. Se llevaron a cabo 2 tipos de análisis. Primeramente, se documentaron los medicamentos antirretrovirales y otros medicamentos que recibían estos pacientes, según el perfil de la farmacia, y se comparó éste con el del récord médico. Segundo, se realizó una comparación detallada de los medicamentos antirretrovirales en 5 momentos distintos durante el período de estudio. El nombre genérico, formulación, dosis y frecuencia de dosificación de los antirretrovirales tal y como aparecían en el récord médico fue comparado con lo que se había registrado en el récord de la farmacia.

RESULTADOS: En total, se emitieron 1607 recetas, de las cuales 1241 correspondían a medicamentos antirretrovirales y 366 medicamentos de otras clases. El primer cernimiento resultó en una discrepancia de $55.1 \%$ (885/1607), de las cuales, $97.2 \%$ fue atribuída a medicamentos de distintas clases, y el $2.9 \%$ (26/885) a los antirretrovirales. La discrepancia de los antirretrovirales fluctuó en distintos momentos entre $5.1 \%$ a $12.6 \%$ cuando se consideraba el nombre genérico sólamente, y fluctuó entre $7.1 \%$ a $17 \%$ cuando se tomaba en consideración la formulación, dosis y frecuencia de dosificación.

CONCLUSIONES: Las discrepancias observadas entre los récords médicos y los de la farmacia corresponden mayormente a medicamentos no antirretrovirales. Para los agentes antirretrovirales, se observaron menos discrepancias, pero aún así, estas fueron significativas. Los resultados indican que el intercambio de información concerniente al uso de medicamentos en esta población de pacientes entre los proveedores de cuidado generalistas y los especialistas en infectología es deficiente.

Wanda T Maldonado

\section{RÉSUMÉ}

OBJECTIF: Comparer et évaluer les notes concernant les médicaments dans les dossiers médicaux de la clientèle externe avec celles dans les dossiers pharmacologiques pour une cohorte de patients infectés par les HIV-1 et traités avec des médicaments antirétroviraux.

MÉTHODOLOGIE: Des données pour 103 patients ont été obtenues du premier janvier 1998 au 31 décembre 1999 à l'aide d'une revue des dossiers médicaux et une collecte des dossiers pharmacologiques. Deux analyses ont été réalisées. En premier, les médicaments antirétroviraux et la médication conjointe dans les dossiers pharmacologiques ont été documentés et comparés aux données à cet effet dans les dossiers médicaux de la clinique externe. En deuxième, une comparaison détaillée a été effectuée à 5 moments spécifiques pendant la période d'étude pour les médicaments antirétroviraux. Les noms génériques, la formulation, la teneur et la posologie des médicaments antirétroviraux tels qu'inscrits dans les dossiers médicaux de la clinique externe ont été comparés à ceux enregistrés dans les dossiers pharmacologiques.

RÉSULTATS: La distribution totale des médicaments était de 1607 soit 366 et 1241 médicaments antirétroviraux et médication conjointe respectivement. Le premier dépistage a résulté en une divergence de $55.1 \%(885 / 1607)$ de laquelle $97.1 \%$ (859/885) a été attribuée à la médication conjointe et $2.9 \%(26 / 885)$ aux médicaments antirétroviraux. La divergence dans les médicaments antirétroviraux à des temps spécifiques s'étalait de $5.1 \%$ à $12.6 \%$ en utilisant le nom générique seulement, et de $7.1 \%$ à $17 \%$ lorsque la formulation, la teneur et la posologie étaient pris en considération.

CONCLUSIONS: La divergence observée entre les dossiers médicaux de la clinique externe et les dossiers pharmacologiques concerne principalement la médication conjointe. Pour les médicaments antirétroviraux, des divergences moindres mais toujours substantielles ont été observées. Ces résultats indiquent qu'un échange complet d'informations concernant l'utilisation de médicaments chez cette population fait défaut entre le médecin généraliste et les spécialistes (maladie infectieuse).

Chantal Guévremont 